\title{
A Control Chart for Gamma Distributed Variables Using Repetitive Sampling Scheme
}

\author{
Nasrullah Khan \\ Department of Statistics \\ University of Veterinary \& Animal Sciences, Lahore (Sub Campus, Jhang), Pakistan \\ nas_shan1@hotmail.com \\ Muhammad Aslam \\ Department of Statistics \\ Faculty of Science, King Abdulaziz University, Jeddah 21551, Saudi Arabia \\ aslam_ravian@hotmail.com \\ Liaquat Ahmad \\ Department of Statistics \\ University of Veterinary \& Animal Sciences, Lahore, Pakistan \\ liaquatahmad@uvas.edu.pk \\ Chi-Hyuck Jun \\ Department of Industrial and Management Engineering \\ POSTECH, Pohang, Republic of Korea \\ chjun@ postech.ac.kr
}

\begin{abstract}
In this manuscript, a control chart is designed when the quality characteristic of interest follows a gamma distribution using repetitive sampling. The Wilson-Hilferty approximation is used to transform the gamma distributed characteristic to a normal random variable. Two pairs of control limits are established and their control constants are determined by considering the specified in-control average run length (ARL). The out-of-control ARL is derived when the process is shifted in terms of the scale parameter of the Gamma distribution. The ARLs are presented for various values of the shape parameter according to process shift parameters. A simulated example is given to illustrate the proposed control chart.
\end{abstract}

Keywords: Wilson-Hilferty transformation, Gamma distribution, Normal distribution Control chart.

\section{Introduction}

The quality of a product depends on the variation in the manufacturing process. This variation in the process may be due to some controllable and uncontrollable factors. The statistical process control (SPC) is one of the powerful tools to minimize the variation in the process. Use of SPC in the industry increases the profit and causes the stability in the market. According to Chase (1997), Arko Paper Products Inc. realized a 1000\% return on investment in 6 months after they adopted an SPC program and their scrap rates dropped from 10.1 to $1.8 \%$. The Shewhart control charts are commonly used in the industry for process monitoring when the quality of interest follows a normal distribution. In practice, it is not always true that the variable of interest follows the normal distribution, but it may follow some non-normal distributions. The distributions of quality characteristics in the chemical process, cutting tool wear process, semiconductor process 
and measurements from the accelerated life test are skewed in nature Derya and Canan (2012). More details about the application and designing of control charts for non-normal distributions can be seen in Nelson (1979), Bai and Choi (1995) and Choobineh and Ballard (1987).

Recently, Santiago and Smith (2013) proposed the control chart called a t-chart when the time between events follows the exponential distribution. They used the variable transformation proposed by Nelson (1994) to transform the exponential distributed data to an approximate normal data. Aslam et al. (2014) proposed a new control chart for the exponential distribution using the transformed variable and repetitive sampling. More details about this type of control charts and applications in variety of fields can be found Das (1955), Stephenson (1966), Ashkar and Bobée (1988), Aksoy (2000), Bhaumik and Gibbons (2006), Borror et al. (2003), Zhang et al. (2007), Dogu (2014).

The gamma distribution has been widely used in a variety of fields. This distribution is considered as a good fit for the waiting time data in life testing. Das (1955) and Stephenson (1966) discussed the application of a gamma distribution to model the rain fall data. Ashkar and Bobée (1988) and Aksoy (2000) presented the applications of this distribution in hydrological data. According to Bhaumik and Gibbons (2006), the twoparameter gamma distribution can be used in environment monitoring and control issues. More details about the applications of gamma distributions can be found in Borror et al. (2003). Zhang et al. (2007) proposed a random-shift model to measure the average run length for a gamma distribution. Recently, Dogu (2014) designed the control chart for a gamma distribution using several change point models.

The control charts available in the literature are designed using the single sampling scheme. Sherman (1965) introduced the repetitive sampling scheme in the area of acceptance sampling plan. Later on, Balamurali and Jun (2006) proved that an acceptance sampling plan using repetitive sampling is more efficient than single and double sampling in term of the average sample number. The designing of control charts for various situations using the repetitive sampling scheme has received the attention these days. Moreover, the repetitive sampling scheme is more efficient than the single sampling scheme in terms of reducing the average run length. The repetitive sampling is operated as follows: a random sample is selected from the production process and information about quality of interest is studied. A decision whether the process is in-control or out-of control is taken on the basis of sample information. Sometimes, it may happen that the decision cannot be reached on the basis of first sample from the production process. In this case, a new sample is selected from the production process and repeated until a decision is reached, see Sherman (1965). This sampling scheme is simple to operate as compared to double and sequential sampling.

Recently, Aslam et al. (2014) proposed an np control chart and an X-bar control chart using repetitive sampling and Ahmad et al. (2013) designed the X-bar control chart based on process capability index using repetitive sampling. Aslam et al. (2014) designed the tchart using repetitive sampling. Aslam et al. (2014) proposed the exponentiated weighted moving average sign chart for repetitive sampling. More details about a variety of control 
charts using various sampling schemes can be seen in Lio et al. (2014), Aslam et al. (2015a, b, c, d), Azam et al. (2015).

Krishnamoorthy et al. (2008) presented an extensive study of various approximations for a gamma distribution. According to Krishnamoorthy et al. (2008), the Wilson-Hilferty (WH) (1931) approximation is a simple, satisfactory and unified approach for addressing various issues for the gamma distribution. According to the best of our knowledge, there is no work on designing the control chart for the gamma distribution using WH approximation. In this paper, we will design a control chart using repetitive sampling by assuming that the quality characteristic of interest follows the gamma distribution. We will use the WH approximation to transform the gamma distributed variable to a normal random variable and to set up the upper and the lower control limits. The control constant of the proposed control chart is determined for a specified in-control average run length (ARL). The out-of-control ARL is derived when the process is shifted in terms of the scale parameter. A simulation example will be given for the illustration purpose.

\section{Proposed control chart for Gamma distribution}

Let $\mathrm{T}$ be a random variable from a gamma distribution with shape parameter a and scale parameter $b$. The cumulative distribution function (cdf) of the gamma distribution is given by

$P(T \leq t)=1-\sum_{j=1}^{a-1} \frac{\left.e^{-\frac{t}{b}(t / b}\right)^{j}}{j !}$

The Wilson and Hilferty (1931) suggested that the transformation of $\mathrm{T}^{*}=\mathrm{T}^{1 / 3}$ is distributed approximately as normal with mean

$\mu_{\mathrm{T}^{*}}=\frac{\mathrm{b}^{1 / 3} \Gamma(\mathrm{a}+1 / 3)}{\Gamma(\mathrm{a})}$

and variance

$\sigma_{\mathrm{T}^{*}}=\frac{\mathrm{b}^{2 / 3} \Gamma(\mathrm{a}+2 / 3)}{\Gamma(\mathrm{a})}-\mu_{\mathrm{T}^{*}}^{2}$

This suggests that $\mathrm{T}^{*}$ is symmetric in distribution, so a control chart can be designed with the usual symmetric type of control limits. Therefore, we propose the following control chart using repetitive sampling for a gamma distributed quality characteristic:

Step 1: Select an item randomly and measure its quality characteristic T. Then, calculate

$\mathrm{T}^{*}=\mathrm{T}^{1 / 3}$

Step 2: Declare the process as out-of-control if $\mathrm{T}^{*} \geq \mathrm{UCL}_{1}$ or $\mathrm{T}^{*} \leq \mathrm{LCL}_{1}$. Declare the process as in-control if $\mathrm{LCL}_{2} \leq \mathrm{T}^{*} \leq \mathrm{UCL}_{2}$. Otherwise, go to Step 1 and repeat the process.

The proposed control chart is based on two pairs of control limits called the inner and the outer control limits. The proposed control chart is the extension of several control charts. 
The proposed chart reduces to Aslam et al. (2014) chart when $a=1$ (an exponential case). The proposed chart reduces to the chart by Santiago and Smith (2013) when $a=$ 1 and $\mathrm{k}_{1}=\mathrm{k}_{2}$. It is assumed here that the control limits have the following forms and that they are constructed from the data when the process is in control. Let $b_{0}$ be the scale parameter when the process is in control. Then, the outer control limits are given by

$\mathrm{LCL}_{1}=\mu_{\mathrm{T}^{*}}-\mathrm{k}_{1} \sigma_{\mathrm{T}^{*}}=\frac{\mathrm{b}_{0}^{1 / 3} \Gamma(\mathrm{a}+1 / 3)}{\Gamma(\mathrm{a})}-\mathrm{k}_{1} \sqrt{\frac{\mathrm{b}_{0}^{2 / 3} \Gamma(\mathrm{a}+2 / 3)}{\Gamma(\mathrm{a})}-\mu_{\mathrm{T}^{*}}^{2}}$

$\mathrm{UCL}_{1}=\mu_{\mathrm{T}^{*}}+\mathrm{k}_{1} \sigma_{\mathrm{T}^{*}}=\frac{\mathrm{b}_{0}^{1 / 3} \Gamma(\mathrm{a}+1 / 3)}{\Gamma(\mathrm{a})}+\mathrm{k}_{1} \sqrt{\frac{\mathrm{b}_{0}^{2 / 3} \Gamma(\mathrm{a}+2 / 3)}{\Gamma(\mathrm{a})}-\mu_{\mathrm{T}^{*}}^{2}}$

The inner control limits are given by

$\mathrm{LCL}_{2}=\mu_{\mathrm{T}^{*}}-\mathrm{k}_{2} \sigma_{\mathrm{T}^{*}}=\frac{\mathrm{b}_{0}^{1 / 3} \Gamma(\mathrm{a}+1 / 3)}{\Gamma(\mathrm{a})}-\mathrm{k}_{2} \sqrt{\frac{\mathrm{b}_{0}^{2 / 3} \Gamma(\mathrm{a}+2 / 3)}{\Gamma(\mathrm{a})}-\mu_{\mathrm{T}^{*}}^{2}}$

$\mathrm{UCL}_{2}=\mu_{\mathrm{T}^{*}}+\mathrm{k}_{2} \sigma_{\mathrm{T}^{*}}=\frac{\mathrm{b}_{0}^{1 / 3} \Gamma(\mathrm{a}+1 / 3)}{\Gamma(\mathrm{a})}+\mathrm{k}_{2} \sqrt{\frac{\mathrm{b}_{0}^{2 / 3} \Gamma(\mathrm{a}+2 / 3)}{\Gamma(\mathrm{a})}-\mu_{\mathrm{T}^{*}}^{2}}$

The control coefficients $\mathrm{k}_{1}$ and $\mathrm{k}_{2}$ are to be determined by considering the specified incontrol ARL.

Define

$$
\begin{aligned}
& \mathrm{LL}_{1}=\left[\frac{\Gamma(\mathrm{a}+1 / 3)}{\Gamma(\mathrm{a})}-\mathrm{k}_{1} \sqrt{\frac{\Gamma(\mathrm{a}+2 / 3)}{\Gamma(\mathrm{a})}-\left(\frac{\Gamma(\mathrm{a}+1 / 3)}{\Gamma(\mathrm{a})}\right)^{2}}\right] \\
& \mathrm{UL}_{1}=\left[\frac{\Gamma(\mathrm{a}+1 / 3)}{\Gamma(\mathrm{a})}+\mathrm{k}_{1} \sqrt{\frac{\Gamma(\mathrm{a}+2 / 3)}{\Gamma(\mathrm{a})}-\left(\frac{\Gamma(\mathrm{a}+1 / 3)^{2}}{\Gamma(\mathrm{a})}\right)^{2}}\right] \\
& \mathrm{LL}_{2}=\left[\frac{\Gamma(\mathrm{a}+1 / 3)}{\Gamma(\mathrm{a})}-\mathrm{k}_{2} \sqrt{\frac{\Gamma(\mathrm{a}+2 / 3)}{\Gamma(\mathrm{a})}-\left(\frac{\Gamma(\mathrm{a}+1 / 3)}{\Gamma(\mathrm{a})}\right)^{2}}\right] \\
& \mathrm{UL}_{2}=\left[\frac{\Gamma(\mathrm{a}+1 / 3)}{\Gamma(\mathrm{a})}+\mathrm{k}_{2} \sqrt{\frac{\Gamma(\mathrm{a}+2 / 3)}{\Gamma(\mathrm{a})}-\left(\frac{\Gamma(\mathrm{a}+1 / 3)}{\Gamma(\mathrm{a})}\right)^{2}}\right]
\end{aligned}
$$


Then, the control limits in Eqs (5) and (6) are reduced to

$$
\begin{aligned}
\mathrm{LCL}_{1} & =\mathrm{b}_{0}^{1 / 3} \mathrm{LL}_{1} \\
\mathrm{UCL}_{1} & =\mathrm{b}_{0}^{1 / 3} \mathrm{UL}_{1} \\
\mathrm{LCL}_{2} & =\mathrm{b}_{0}^{1 / 3} \mathrm{LL}_{2} \\
\mathrm{UCL}_{2} & =\mathrm{b}_{0}^{1 / 3} \mathrm{UL}_{2}
\end{aligned}
$$

Note that $\mathrm{LL}_{1}, \mathrm{UL}_{1}, \mathrm{LL}_{2}$ and $\mathrm{UL}_{2}$ do not depend on the scale parameter $\mathrm{b}_{0}$.

It is assumed that only the scale parameter of the gamma distribution will be changed when the process shift occurs. That is, the shape parameter remains unchanged even when the process is shifted. The shape parameter is usually differently fixed depending on a particular type of application similarly to the Weibull case Jun et al. (2006). Let $b_{0}$ be the scale parameter when the process is in control and let $b_{1}$ be the scale parameter when the process is shifted. Further, the scale parameter for the shifted process has the form of $\mathrm{b}_{1}=c \mathrm{~b}_{0}$ for a constant $\mathrm{c}$.

Under the proposed control chart, the probability that the process is declared as out of control for a single sample is given by below when the process is actually in control.

$$
\mathrm{P}_{\text {out }, 1}^{0}=\mathrm{P}\left(\mathrm{T}^{*}<\mathrm{LCL}_{1} \mid \mathrm{b}=\mathrm{b}_{0}\right)+\mathrm{P}\left(\mathrm{T}^{*}>U C L_{1} \mid \mathrm{b}=\mathrm{b}_{0}\right)
$$

or

$$
\mathrm{P}_{\mathrm{out}, 1}^{0}=1-\sum_{\mathrm{j}=1}^{\mathrm{a}-1} \frac{\mathrm{e}^{-\mathrm{LL}_{1}{ }^{3}\left(\mathrm{LL}_{1}{ }^{3}\right)^{\mathrm{j}}}}{\mathrm{j} !}+\sum_{\mathrm{j}=1}^{\mathrm{a}-1} \frac{\mathrm{e}^{-\mathrm{UL}^{3}}\left(\mathrm{UL}_{1}{ }^{3}\right)^{\mathrm{j}}}{\mathrm{j} !}
$$

The probability of repetition $\left(\mathrm{P}_{\text {rep }}^{0}\right)$ for the proposed control chart is given as follows

$$
\mathrm{P}_{\text {rep }}^{0}=\mathrm{P}\left\{\mathrm{UCL}_{2}<T^{*}<\mathrm{UCL}_{1} \mid \mathrm{b}=\mathrm{b}_{0}\right\}+\mathrm{P}\left\{\mathrm{LCL}_{1}<T^{*}<\mathrm{LCL}_{2} \mid \mathrm{b}=\mathrm{b}_{0}\right\}
$$

or

$$
P_{\text {rep }}^{0}=\sum_{j=1}^{\mathrm{a}-1} \frac{\mathrm{e}^{-\mathrm{UL}_{2}{ }^{3}\left(\mathrm{UL}_{2}{ }^{3}\right)^{\mathrm{j}}}}{\mathrm{j} !}-\sum_{\mathrm{j}=1}^{\mathrm{a}-1} \frac{\mathrm{e}^{-\mathrm{UL}_{1}{ }^{3}\left(\mathrm{UL}_{1}{ }^{3}\right)^{\mathrm{j}}}}{\mathrm{j} !}+\sum_{\mathrm{j}=1}^{\mathrm{a}-1} \frac{\mathrm{e}^{-\mathrm{LL}_{1}{ }^{3}\left(\mathrm{LL}_{1}{ }^{3}\right)^{\mathrm{j}}}}{\mathrm{j} !}-\sum_{\mathrm{j}=1}^{\mathrm{a}-1} \frac{\mathrm{e}^{-\mathrm{LL}_{2}{ }^{3}\left(\mathrm{LL}_{2}{ }^{3}\right)^{\mathrm{j}}}}{\mathrm{j} !}
$$

It should be noted that the control limits, $\mathrm{P}_{\text {out }, 1}^{0}$ and $\mathrm{P}_{\text {rep }}^{0}$ only depend on shape parameter a which is assumed to be known in this study. The shape parameter a can be estimated from the data when it is unknown. It should also be noted that the above probabilities are exact under the gamma distribution instead of a normal approximation. The normal approximation is utilized only when establishing the symmetric control limits. The probability of declaring as out-of-control under repetitive sampling is given as

$\mathrm{P}_{\mathrm{out}}^{0}=\frac{\mathrm{P}_{\mathrm{out}, 1}^{0}}{1-\mathrm{P}_{\mathrm{rep}}^{0}}$ 
The average run length (ARL) for the in-control process is given as follows:

$\mathrm{ARL}_{0}=\frac{1}{\mathrm{P}_{\mathrm{out}}^{0}}$

Now, we assume that the scale parameter of the gamma distribution is changed from $b_{0}$ to $b_{1}=c b_{0}$, for a constant $c$. The probability of declaring as out- of- control for the shifted process based on a single sample is given as follows

$\mathrm{P}_{\text {out }, 1}^{1}=\mathrm{P}\left(\mathrm{T}^{*}<\mathrm{LCL} \mid \mathrm{b}=\mathrm{b}_{1}\right)+\mathrm{P}\left(\mathrm{T}^{*}>U C L \mid \mathrm{b}=\mathrm{b}_{1}\right)$

$=1-\sum_{j=1}^{a-1} \frac{e^{-\frac{L L_{1}{ }^{3}}{c}\left(\frac{L L_{1}{ }^{3}}{c}\right)^{j}}}{j !}+\sum_{j=1}^{a-1} \frac{e^{-\frac{U L_{1}^{3}}{c}\left(\frac{U L_{1}^{3}}{c}\right)^{j}}}{j !}$

The probability of repetition under repetitive sampling is given as follows

$$
\begin{aligned}
& \mathrm{P}_{\text {rep }}^{1}=\mathrm{P}\left\{\mathrm{UCL}_{2}<T^{*}<\mathrm{UCL}_{1} \mid \mathrm{b}=\mathrm{b}_{0}\right\}+\mathrm{P}\left\{\mathrm{LCL}_{1}<T^{*}<\mathrm{LCL}_{2} \mid \mathrm{b}=\mathrm{b}_{0}\right\} \\
& =\sum_{\mathrm{j}=1}^{\mathrm{a}-1} \frac{\mathrm{e}^{-\frac{\mathrm{UL}_{2}{ }^{3}}{\mathrm{c}}\left(\frac{\mathrm{UL}_{2}}{\mathrm{c}}\right)^{\mathrm{j}}}}{\mathrm{j} !}-\sum_{\mathrm{j}=1}^{\mathrm{a}-1} \frac{\mathrm{e}^{\frac{-\mathrm{UL}_{1}{ }^{3}}{\mathrm{c}}}\left(\frac{\mathrm{UL}_{1}{ }^{3}}{\mathrm{c}}\right)^{\mathrm{j}}}{\mathrm{j} !}+\sum_{\mathrm{j}=1}^{\mathrm{a}-1} \frac{\mathrm{e}^{\frac{-\mathrm{LL}_{1}{ }^{3}}{\mathrm{c}}\left(\frac{\mathrm{LL}_{1}}{\mathrm{c}}\right)^{\mathrm{j}}}}{\mathrm{j} !}-\sum_{\mathrm{j}=1}^{\mathrm{a}-1} \frac{\mathrm{e}^{\frac{-\mathrm{LL}_{2}{ }^{3}}{\mathrm{c}}}\left(\frac{\mathrm{LL}_{2}{ }^{3}}{\mathrm{c}}\right)^{\mathrm{j}}}{\mathrm{j} !}
\end{aligned}
$$

Therefore, the probability of declaring as out-of control for the shifted process is given as

$$
\mathrm{P}_{\mathrm{out}}^{1}=\frac{\mathrm{P}_{\mathrm{out}, 1}^{1}}{1-\mathrm{P}_{\mathrm{rep}}^{1}}
$$

The out-of-control ARL for the shifted process is given as follows

$\mathrm{ARL}_{1}=\frac{1}{\mathrm{P}_{\text {out }}^{1}}$

We first determine the values of $\mathrm{k}_{1}$ and $\mathrm{k}_{2}$ for each of various shape parameters of the gamma distribution so that $\mathrm{ARL}_{0}$, is close to the specified in-control ARL. Then, the outof-control ARL $\left(\mathrm{ARL}_{1}\right)$ will be obtained according to various shifts in the scale parameter. Tables 1-3 report the out-of-control ARLs for $\mathrm{ARL}_{0}=200,300$ and 370, respectively. 
Table 1: The values of $A R L_{1}$ when $A R L_{0}=200$

\begin{tabular}{|c|c|c|c|c|c|}
\hline & $\mathrm{a}=1$ & $\mathrm{a}=2$ & $\mathrm{a}=5$ & $\mathrm{a}=10$ & $\mathrm{a}=20$ \\
\cline { 2 - 6 } $\mathrm{c}$ & $\mathrm{k}_{1}=3.053036$ & $\mathrm{k}_{1}=3.267858$ & $\mathrm{k}_{1}=4.427538$ & $\mathrm{k}_{1}=8.199072$ & $\mathrm{k}_{1}=8.006176$ \\
\cline { 2 - 6 } & $\mathrm{k}_{2}=0.332165$ & $\mathrm{k}_{2}=2.681024$ & $\mathrm{k}_{2}=3.781105$ & $\mathrm{k}_{2}=3.794553$ & $\mathrm{k}_{2}=4.078875$ \\
\cline { 2 - 6 } & $\mathrm{ARL}_{1}$ & $\mathrm{ARL}_{1}$ & $\mathrm{ARL}_{1}$ & $\mathrm{ARL}_{1}$ & $\mathrm{ARL}_{1}$ \\
\hline 1.00 & 200.59 & 200.02 & 200.66 & 200.38 & 200.20 \\
\hline 1.01 & 187.28 & 187.24 & 183.19 & 138.24 & 142.82 \\
\hline 1.02 & 175.08 & 175.52 & 167.58 & 96.15 & 102.62 \\
\hline 1.03 & 163.87 & 164.74 & 153.59 & 67.42 & 74.28 \\
\hline 1.04 & 153.57 & 154.81 & 141.04 & 47.68 & 54.16 \\
\hline 1.05 & 144.09 & 145.66 & 129.75 & 34.02 & 39.79 \\
\hline 1.10 & 106.51 & 109.27 & 87.69 & 7.40 & 9.72 \\
\hline 1.15 & 80.73 & 84.11 & 61.56 & 2.43 & 3.22 \\
\hline 1.20 & 62.57 & 66.21 & 44.67 & 1.36 & 1.63 \\
\hline 1.30 & 39.78 & 43.42 & 25.57 & 1.03 & 1.07 \\
\hline 1.40 & 26.96 & 30.30 & 16.03 & 1.00 & 1.01 \\
\hline 1.50 & 19.24 & 22.23 & 10.81 & 1.00 & 1.00 \\
\hline 1.60 & 14.34 & 16.97 & 7.74 & 1.00 & 1.00 \\
\hline 1.70 & 11.09 & 13.40 & 5.83 & 1.00 & 1.00 \\
\hline 1.80 & 8.84 & 10.88 & 4.57 & 1.00 & 1.00 \\
\hline 1.90 & 7.24 & 9.05 & 3.72 & 1.00 & 1.00 \\
\hline 2.00 & 6.07 & 7.67 & 3.12 & 1.00 & 1.00 \\
\hline 2.50 & 3.24 & 4.19 & 1.78 & 1.00 & 1.00 \\
\hline 3.00 & 2.25 & 2.88 & 1.37 & 1.00 & 1.00 \\
\hline
\end{tabular}

Table 2: The values of $A R L_{1}$ when $A L_{0}=300$

\begin{tabular}{|c|c|c|c|c|c|}
\hline \multirow{3}{*}{$\mathrm{c}$} & $\mathrm{a}=1$ & $\mathrm{a}=2$ & $\mathrm{a}=5$ & $\mathrm{a}=10$ & $\mathrm{a}=20$ \\
\cline { 2 - 6 } & $\mathrm{k}_{1}=3.53201$ & $\mathrm{k}_{1}=3.416441$ & $\mathrm{k}_{1}=4.745671$ & $\mathrm{k}_{1}=7.128007$ & $\mathrm{k}_{1}=7.734877$ \\
\cline { 2 - 6 } & $\mathrm{k}_{2}=0.081593$ & $\mathrm{k}_{2}=2.027647$ & $\mathrm{k}_{2}=2.201156$ & $\mathrm{k}_{2}=1.41065$ & $\mathrm{k}_{2}=4.656098$ \\
\cline { 2 - 6 } & $\mathrm{ARL}_{1}$ & $\mathrm{ARL}_{1}$ & $\mathrm{ARL}_{1}$ & $\mathrm{ARL}_{1}$ & $\mathrm{ARL}_{1}$ \\
\hline 1.00 & 300.44 & 300.30 & 300.93 & 300.38 & 300.57 \\
\hline 1.01 & 275.53 & 278.85 & 265.39 & 218.82 & 226.28 \\
\hline 1.02 & 253.09 & 259.31 & 234.61 & 160.45 & 171.34 \\
\hline 1.03 & 232.85 & 241.47 & 207.89 & 118.41 & 130.47 \\
\hline 1.04 & 214.56 & 225.16 & 184.63 & 87.95 & 99.91 \\
\hline 1.05 & 198.00 & 210.23 & 164.35 & 65.75 & 76.94 \\
\hline 1.10 & 135.35 & 151.96 & 94.78 & 17.04 & 22.72 \\
\hline 1.15 & 95.53 & 112.93 & 57.37 & 5.47 & 7.89 \\
\hline 1.20 & 69.37 & 86.00 & 36.26 & 2.38 & 3.39 \\
\hline 1.30 & 39.36 & 53.07 & 16.27 & 1.17 & 1.36 \\
\hline 1.40 & 24.24 & 35.08 & 8.39 & 1.03 & 1.07 \\
\hline 1.50 & 15.99 & 24.51 & 4.91 & 1.01 & 1.02 \\
\hline 1.60 & 11.16 & 17.92 & 3.22 & 1.00 & 1.00 \\
\hline 1.70 & 8.19 & 13.62 & 2.34 & 1.00 & 1.00 \\
\hline 1.80 & 6.27 & 10.69 & 1.85 & 1.00 & 1.00 \\
\hline 1.90 & 4.98 & 8.62 & 1.56 & 1.00 & 1.00 \\
\hline 2.00 & 4.08 & 7.13 & 1.39 & 1.00 & 1.00 \\
\hline 2.50 & 2.13 & 3.59 & 1.09 & 1.00 & 1.00 \\
\hline 3.00 & 1.56 & 2.39 & 1.03 & 1.00 & 1.00 \\
\hline
\end{tabular}


Table 3: The values of $A R L_{1}$ when $A R L_{0}=370$

\begin{tabular}{|c|c|c|c|c|c|}
\hline \multirow{4}{*}{$\mathrm{c}$} & $a=1$ & $a=2$ & $a=5$ & $a=10$ & $a=20$ \\
\hline & $\begin{array}{c}\mathrm{k}_{1}=2.82152 \\
1\end{array}$ & $\begin{array}{c}\mathrm{k}_{1}=3.54827 \\
3\end{array}$ & $\begin{array}{c}\mathrm{k}_{1}=4.72527 \\
4\end{array}$ & $\begin{array}{c}\mathrm{k}_{1}=5.80871 \\
1\end{array}$ & $\begin{array}{c}\mathrm{k}_{1}=8.28060 \\
4\end{array}$ \\
\hline & $\begin{array}{c}\mathrm{k}_{2}=2.69969 \\
2\end{array}$ & $\begin{array}{c}\mathrm{k}_{2}=1.36472 \\
6\end{array}$ & $\begin{array}{c}\mathrm{k}_{2}=2.47768 \\
1\end{array}$ & $\begin{array}{c}\mathrm{k}_{2}=4.35825 \\
1\end{array}$ & $\begin{array}{c}\mathrm{k}_{2}=3.79775 \\
3\end{array}$ \\
\hline & $\mathrm{ARL}_{1}$ & $\mathrm{ARL}_{1}$ & $\mathrm{ARL}_{1}$ & $\mathrm{ARL}_{1}$ & $\mathrm{ARL}_{1}$ \\
\hline 1.00 & 370.84 & 370.12 & 370.96 & 370.38 & 370.89 \\
\hline 1.01 & 349.72 & 340.62 & 328.76 & 321.63 & 253.17 \\
\hline 1.02 & 330.18 & 313.97 & 292.05 & 280.13 & 174.17 \\
\hline 1.03 & 312.08 & 289.85 & 260.03 & 244.70 & 120.77 \\
\hline 1.04 & 295.29 & 267.97 & 232.03 & 214.35 & 84.41 \\
\hline 1.05 & 279.69 & 248.11 & 207.49 & 188.27 & 59.47 \\
\hline 1.10 & 216.42 & 172.25 & 122.29 & 102.26 & 11.88 \\
\hline 1.15 & 171.22 & 123.30 & 75.47 & 58.84 & 3.33 \\
\hline 1.20 & 138.12 & 90.67 & 48.53 & 35.62 & 1.56 \\
\hline 1.30 & 94.44 & 52.54 & 22.35 & 14.94 & 1.05 \\
\hline 1.40 & 68.16 & 32.89 & 11.67 & 7.36 & 1.01 \\
\hline 1.50 & 51.37 & 21.92 & 6.80 & 4.20 & 1.00 \\
\hline 1.60 & 40.10 & 15.40 & 4.38 & 2.73 & 1.00 \\
\hline 1.70 & 32.23 & 11.32 & 3.09 & 2.00 & 1.00 \\
\hline 1.80 & 26.53 & 8.64 & 2.35 & 1.61 & 1.00 \\
\hline 1.90 & 22.29 & 6.82 & 1.91 & 1.39 & 1.00 \\
\hline 2.00 & 19.06 & 5.54 & 1.63 & 1.25 & 1.00 \\
\hline 2.50 & 10.50 & 2.70 & 1.15 & 1.04 & 1.00 \\
\hline 3.00 & 7.05 & 1.85 & 1.05 & 1.01 & 1.00 \\
\hline
\end{tabular}

From Tables 1-3, we note the following trend:

1. For the same values of $a, \mathrm{ARL}_{1}$ decreases as $c$ increases.

2. There is no specific trend in value of $\mathrm{k}$ as the shape parameter increases.

3. $\mathrm{ARL}_{1}$ decreases rapidly as value of $c$ increases.

\section{Advantages of the Proposed Chart}

Santiago and Smith (2013) designed the t-chart when the time between events follows the exponential distribution. In this section, the performance of the proposed control chart is compared with t-chart by Santiago and Smith (2013) for the exponential distribution because gamma distribution reduces to the exponential distribution when $a=1$. In Table 4 we compare the performance of two control chart for the same values of shifts and other specified parameters in terms of ARLs values. A control chart having the smaller values of ARLs for the same specified parameters is said to be more efficient. We see from the Table 4 that the proposed control provides the smaller values of $\mathrm{ARL}_{1}$ for 
various values as compared to existing control chart. For example, when $\mathrm{ARL}_{0}=370$ and $c=1.1$, the proposed control provides $\mathrm{ARL}_{1}=216$, while it is 244 from the chart by proposed by Santiago and Smith (2013). So, the proposed control chart performs better than control charts proposed by Santiago and Smith (2013) in terms of detecting early shift in the manufacturing process.

Table 4: Comparison of Proposed Chart with Santiago and Smith (2013) charts when $r_{0}=370$

\begin{tabular}{|c|c|c|}
\hline \multirow{4}{*}{$\mathrm{c}$} & $a=1$ & \multirow[t]{4}{*}{ Santiago and Smith (2013) } \\
\hline & $\mathrm{k}_{1}=2.82$ & \\
\hline & $\mathrm{k}_{2}=2.69$ & \\
\hline & Proposed & \\
\hline 1.00 & 370.84 & 370.00 \\
\hline 1.01 & 349.72 & 355.00 \\
\hline 1.02 & 330.18 & 340.54 \\
\hline 1.03 & 312.08 & 326.64 \\
\hline 1.04 & 295.29 & 313.29 \\
\hline 1.05 & 279.69 & 300.48 \\
\hline 1.10 & 216.42 & 244.23 \\
\hline 1.15 & 171.22 & 199.59 \\
\hline 1.20 & 138.12 & 164.43 \\
\hline 1.30 & 94.44 & 114.85 \\
\hline 1.40 & 68.16 & 83.42 \\
\hline 1.50 & 51.37 & 62.82 \\
\hline 1.60 & 40.1 & 48.85 \\
\hline 1.70 & 32.23 & 39.04 \\
\hline 1.80 & 26.53 & 31.95 \\
\hline 1.90 & 22.29 & 26.69 \\
\hline 2.00 & 19.06 & 22.68 \\
\hline 2.50 & 10.5 & 12.19 \\
\hline 3.00 & 7.05 & 8.04 \\
\hline
\end{tabular}

The efficiency of proposed chart is also compared with existing control chart for the gamma distribution. Again, the values of $\mathrm{ARL}_{1}$ are placed in Table 5 for both control charts for same values of specified parameters. From Table 5, we note that the proposed chart performs better than existing control chart for gamma distribution at all values of shifts. For example, when $\mathrm{ARL}_{0}=370, a=2$ and $c=1.1$, the proposed control provides $\mathrm{ARL}_{1}=122$, while it is 192 from the existing chart. So, the proposed control chart performs better in terms of detecting early shift in the manufacturing process. 
Table 5: Comparison of Proposed Chart with existing gamma charts when $r_{0}=370$

\begin{tabular}{|c|c|c|}
\hline \multirow{2}{*}{$\mathrm{c}$} & $\mathrm{a}=2$ & \multirow{2}{*}{$\begin{array}{c}\text { Existing chart when } \\
\mathrm{a}=2\end{array}$} \\
\cline { 2 - 2 } & $\mathrm{k}_{1}=4.72$ & \multirow{2}{*}{$\mathrm{k}_{1}=\mathrm{k}_{2}=\mathrm{k}$} \\
\cline { 2 - 2 } & $\mathrm{k}_{2}=2.47$ & \\
\cline { 2 - 2 } & Proposed & 370.00 \\
\hline 1.00 & 370.96 & 344.44 \\
\hline 1.01 & 328.76 & 321.12 \\
\hline 1.02 & 292.05 & 299.81 \\
\hline 1.03 & 260.03 & 280.30 \\
\hline 1.04 & 232.03 & 262.42 \\
\hline 1.05 & 207.49 & 192.35 \\
\hline 1.10 & 122.29 & 145.07 \\
\hline 1.15 & 75.47 & 112.18 \\
\hline 1.20 & 48.53 & 71.42 \\
\hline 1.30 & 22.35 & 48.71 \\
\hline 1.40 & 11.67 & 35.07 \\
\hline 1.50 & 6.80 & 26.39 \\
\hline 1.60 & 4.38 & 20.59 \\
\hline 1.70 & 3.09 & 16.55 \\
\hline 1.80 & 2.35 & 13.64 \\
\hline 1.90 & 1.91 & 11.48 \\
\hline 2.00 & 1.63 & 6.07 \\
\hline 2.50 & 1.15 & 4.05 \\
\hline 3.00 & 1.05 & \\
\hline & & \\
\hline
\end{tabular}

\section{Simulation Study}

Now, we will discuss the application of the proposed control chart using the simulated data. First 30 observations of the data is generated from the gamma distribution assuming that process is in control when $a=1$. Let $r_{0}=370$. Next 35 observations are generated from the gamma distribution by assuming that process has shifted to $b_{1}=1.7 b_{0}$ $(c=1.7)$. The data of 30 observations is reported in Table 6 .

Table 6: Data of 30 observations from a gamma distribution

\begin{tabular}{|c|c|c|c|c|c|}
\hline Sample \# & T & Sample\# & T & Sample\# & $\mathrm{T}$ \\
\hline 1 & 0.3557 & 11 & 0.4296 & 21 & 0.0597 \\
\hline 2 & 0.8709 & 12 & 0.8914 & 22 & 0.8059 \\
\hline 3 & 1.1496 & 13 & 0.1014 & 23 & 0.7271 \\
\hline 4 & 1.7524 & 14 & 0.1210 & 24 & 0.6041 \\
\hline 5 & 2.9577 & 15 & 1.3688 & 25 & 1.6952 \\
\hline 6 & 2.3009 & 16 & 0.1662 & 26 & 0.6740 \\
\hline 7 & 0.3100 & 17 & 1.0774 & 27 & 0.8610 \\
\hline 8 & 0.8291 & 18 & 4.0056 & 28 & 0.3215 \\
\hline 9 & 2.1613 & 19 & 0.6820 & 29 & 0.5248 \\
\hline 10 & 1.5632 & 20 & 0.8878 & 30 & 0.0329 \\
\hline
\end{tabular}


The transformed data $\mathrm{T}^{*}=\mathrm{T}^{1 / 3}$ is given in Table 7 .

Table 7: Transformed data using transformation $\mathbf{T}^{*}$

\begin{tabular}{|c|c|c|c|c|c|}
\hline Sample \# & $\mathrm{T}^{*}$ & Sample\# & $\mathrm{T}^{*}$ & Sample\# & $\mathrm{T}^{*}$ \\
\hline 1 & 0.7086 & 11 & 0.7545 & 21 & 0.3910 \\
\hline 2 & 0.9549 & 12 & 0.9624 & 22 & 0.9306 \\
\hline 3 & 1.0475 & 13 & 0.4663 & 23 & 0.8992 \\
\hline 4 & 1.2056 & 14 & 0.4946 & 24 & 0.8453 \\
\hline 5 & 1.4354 & 15 & 1.1103 & 25 & 1.1923 \\
\hline 6 & 1.3201 & 16 & 0.5498 & 26 & 0.8767 \\
\hline 7 & 0.6768 & 17 & 1.0251 & 27 & 0.9513 \\
\hline 8 & 0.9394 & 18 & 1.5881 & 28 & 0.6850 \\
\hline 9 & 1.2929 & 19 & 0.8802 & 29 & 0.8066 \\
\hline 10 & 1.1605 & 20 & 0.9611 & 30 & 0.3207 \\
\hline
\end{tabular}

The four limits are obtained by $L C L_{1}=-0.0223, L C L_{2}=0.0199, U C L_{2}=1.7660$ and $U C L_{1}=1.8082$. We plotted the transformed data $\mathrm{T}^{*}=\mathrm{T}^{1 / 3}$ on the control chart in Figure 1.

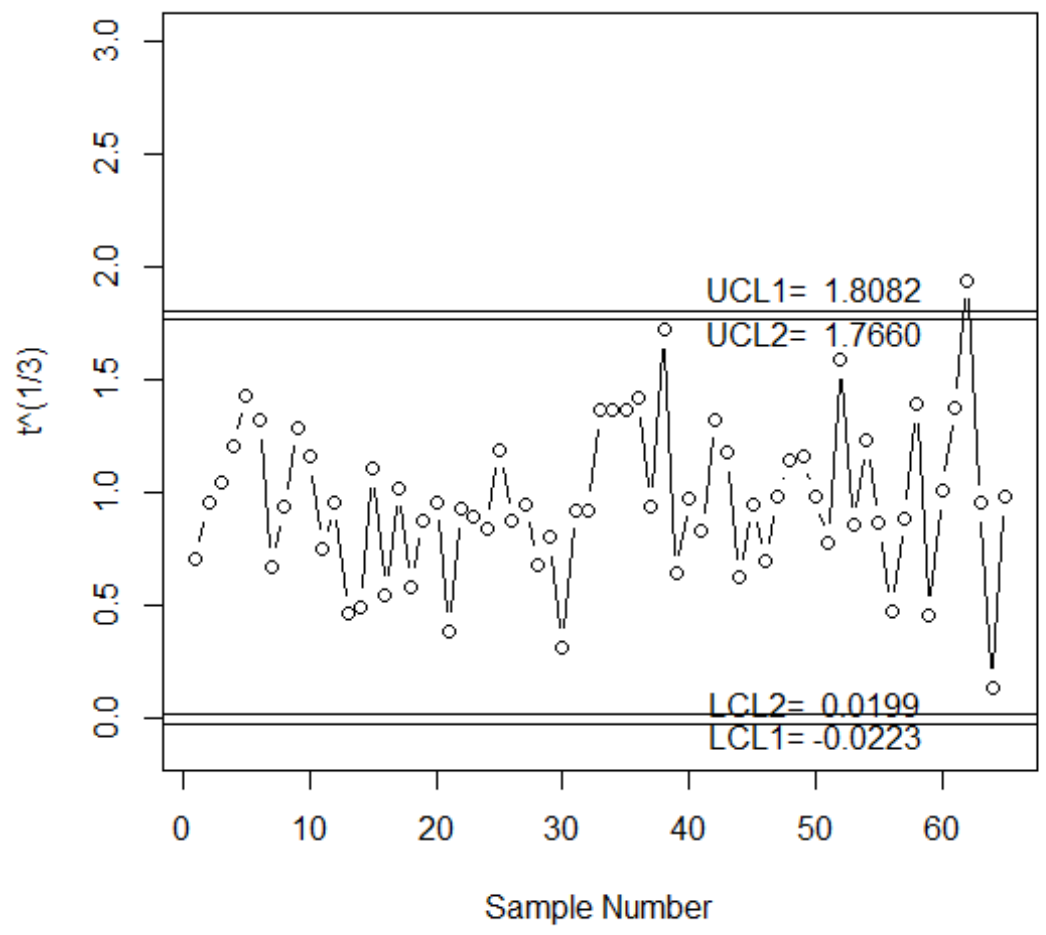

Figure 1: The proposed chart for simulated data 
From this control chart, we can see that the proposed chart detects the shift at 32th observation. We also plotted 30 values on control chart by Santiago and Smith (2013) in Figure 2.

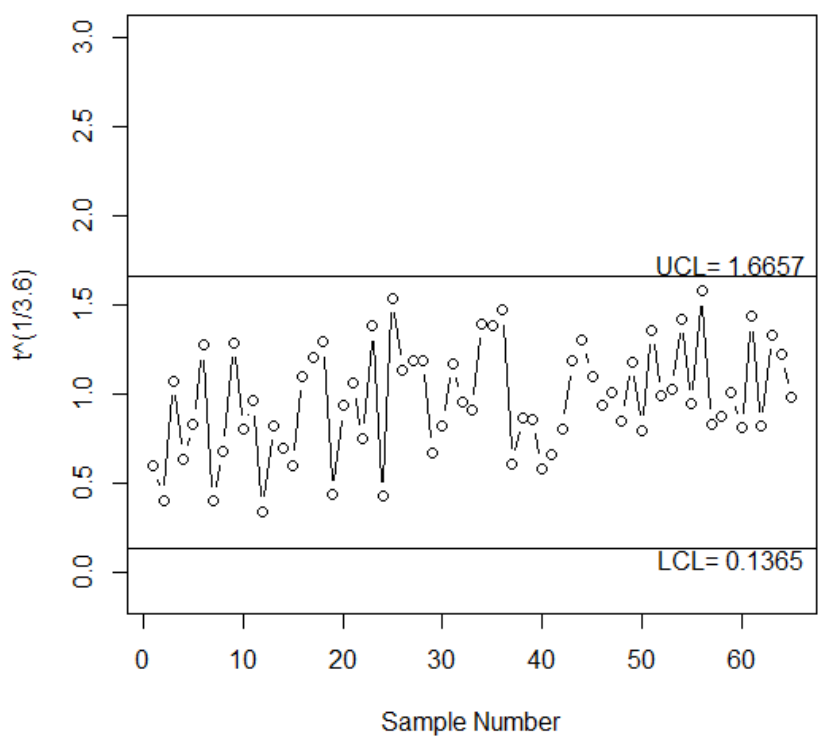

Figure 2: Existing chart for the simulated data

From Fig. 2, we note that the control chart by Santiago and Smith (2013) does not detect the shift. So, the proposed chart has ability to detect the shift in the process earlier as compared to the existing control chart.

\section{Application of Proposed Chart}

For the application of proposed chart, monitoring of urinary tract infections (UTIs) data about duration of male UTIs patient is selected from large hospital. The similar data was considered by Santiago and Smith (2013). The UTIs data follows the gamma distribution with $a=5$. Let $r_{0}=370$ for this in-control UTIs data. The data is shown in Table 8 . The control limits for UTIs data are shown in Figure 3.

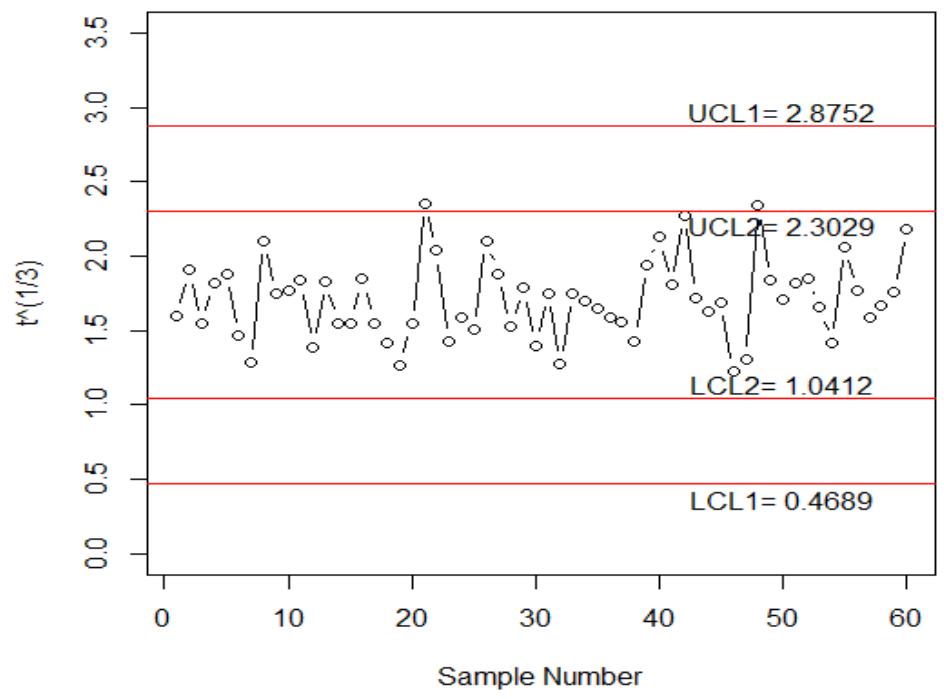

Figure 3: The chart for UTIs data 
By plotting the statistic $\mathrm{T}^{*}$ on control chart in Figure 3, it can be seen that several values of $\mathrm{T}^{*}$ are near to $L C L_{2}$ and $U C L_{2}$ and two values lie in repetitive area. The Figure 3 , clearly indicates that cause of variation in the process should be indicated.

\section{Table 8: The UTIs data}

\begin{tabular}{|c|c|c|c|c|c|}
\hline Sample \# & $\mathrm{T}^{*}$ & Sample \# & $\mathrm{T}^{*}$ & Sample \# & $\mathrm{T}^{*}$ \\
\hline 1 & 1.5989 & 21 & 2.3554 & 41 & 1.8089 \\
\hline 2 & 1.9088 & 22 & 2.0375 & 42 & 2.2751 \\
\hline 3 & 1.5430 & 23 & 1.4223 & 43 & 1.7196 \\
\hline 4 & 1.8190 & 24 & 1.5916 & 44 & 1.6306 \\
\hline 5 & 1.8835 & 25 & 1.5047 & 45 & 1.6914 \\
\hline 6 & 1.4631 & 26 & 2.1053 & 46 & 1.2228 \\
\hline 7 & 1.2838 & 27 & 1.8844 & 47 & 1.3023 \\
\hline 8 & 2.1045 & 28 & 1.5275 & 48 & 2.3409 \\
\hline 9 & 1.7457 & 29 & 1.7886 & 49 & 1.8352 \\
\hline 10 & 1.7651 & 30 & 1.4014 & 50 & 1.7123 \\
\hline 11 & 1.8374 & 31 & 1.7503 & 51 & 1.8181 \\
\hline 12 & 1.3895 & 32 & 1.2716 & 52 & 1.8539 \\
\hline 13 & 1.8341 & 33 & 1.7535 & 53 & 1.6534 \\
\hline 14 & 1.5507 & 34 & 1.7035 & 54 & 1.4182 \\
\hline 15 & 1.5522 & 35 & 1.6461 & 55 & 2.0628 \\
\hline 16 & 1.8457 & 36 & 1.5905 & 56 & 1.7667 \\
\hline 17 & 1.5502 & 37 & 1.5605 & 57 & 1.5866 \\
\hline 18 & 1.4127 & 38 & 1.4286 & 58 & 1.6654 \\
\hline 19 & 1.2637 & 39 & 1.9444 & 59 & 1.7574 \\
\hline 20 & 1.5467 & 40 & 2.1286 & 60 & 2.1864 \\
\hline
\end{tabular}

\section{Concluding Remarks}

We proposed a new control chart for the gamma distribution. The WH transformation is used to establish the symmetric control limits of the proposed control chart. Tables are provided for practical use and comparison is made with the existing control chart. The proposed control chart is found to outperform the control chart proposed by Santiago and Smith (2013) and Aslam et al. (2014). The application of the proposed control chart is given with the help of a simulated data. The proposed control chart can be used in the industry for the manufacturing process when the time between events follows the exponential distribution or gamma distribution with known or unknown shape parameter. The proposed control chart will be extended using the other sampling schemes as a future research.

\section{Acknowledgements}

The authors are deeply thankful to Editor and reviewers for their valuable suggestions to improve the quality of paper. The authors are deeply thankful to editor and reviewers for their valuable suggestions to improve the quality of this manuscript. This article was funded by the Deanship of Scientific Research (DSR), King Abdulaziz University, 
Jeddah. The author, Muhammad Aslam, therefore, acknowledge with thanks DSR technical and financial support.

\section{References}

1. Chase, N. (1997). SPC provides 1000\% ROI. Quality, 36, 62-63.

2. Derya, K. and Canan, H. (2012). Control Charts for Skewed Distributions: Weibull, Gamma, and Lognormal. Advances in Methodology \& Statistics/Metodoloski zvezki, 9(2), 95-106.

3. Nelson, P.R. (1979). Control charts for Weibull processes with standards given. Reliability, IEEE Transactions, 28(4), 283-288.

4. Bai, D. and Choi, I. (1995). (X) OVER-BAR-CONTROL AND R-CONTROL CHARTS FOR SKEWED POPULATIONS, Journal of Quality Technology,. 27(2), 120-131.

5. Choobineh, F. and Ballard, J. (1987). Control-limits of QC Charts for skewed distributions using weighted-variance, Reliability, IEEE Transactions, 36(4), 473477.

6. Santiago, E. and Smith, J. (2013). Control charts based on the exponential distribution: Adapting runs rules for the t chart, Quality Engineering, 25(2), 8596.

7. Nelson, L.S. (1994). A control chart for parts-per-million nonconforming items, Journal of Quality Technology, 26(3), 239-240.

8. Aslam, M., Khan, N., Azam, M., and Jun, C. H. (2014). Designing of a new monitoring t-chart using repetitive sampling. Information Sciences, 269, 210-216.

9. Das, S. (1955). The fitting of truncated type III curves to daily rainfall data, Australian Journal of Physics, 8(2), 298-304.

10. Stephenson, D. B., Kumar, K. R., Doblas-Reyes, F. J., Royer, J. F., Chauvin, F., and Pezzulli, S. (1999). Extreme daily rainfall events and their impact on ensemble forecasts of the Indian monsoon. Monthly Weather Review, 127(9), 1954-1966.

11. Ashkar, F., and Bobée, B. (1988). Confidence intervals for flood events under a Pearson 3 or log Pearson 3 distribution. Water Resources Bulletin, 24(3), 639650.

12. Aksoy, H. (2000). Use of gamma distribution in hydrological analysis. Turkish Journal of Engineering and Environmental Sciences, 24(6), 419-428.

13. Bhaumik, D.K. and Gibbons, R.D. (2006). One-sided approximate prediction intervals for at least $\mathrm{p}$ of $\mathrm{m}$ observations from a gamma population at each of $\mathrm{r}$ locations, Technometrics, 48(1), 112-119.

14. Borror, C.M., Keats, J.B and Montgomery, D.C. (2003). Robustness of the time between events CUSUM. International Journal of Production Research, 41(15), 3435-3444.

15. Zhang, C. W., Xie, M., Liu, J. Y., and Goh, T. N. (2007). A control chart for the Gamma distribution as a model of time between events. International Journal of Production Research, 45(23), 5649-5666. 
16. Dogu, E. (2014). Change point estimation based statistical monitoring with variable time between events (TBE) control charts. Quality Technology \& Quantitative Management, 11(4), 383-400.

17. Sherman, R.E.(1965). Design and evaluation of a repetitive group sampling plan. Technometrics, 7(1), 11-21.

18. Balamurali, S. and Jun, C.-h. (2006). Repetitive group sampling procedure for variables inspection, Journal of Applied Statistics, 33(3), 327-338.

19. Aslam, M., Azam, M., and Jun, C. H. (2014). New attributes and variables control charts under repetitive sampling. Industrial Engineering \& Management Systems, 13(1), 101-106.

20. Ahmad, L., Aslam, M., and Jun, C.-H. (2014). Designing of X-bar control charts based on process capability index using repetitive sampling. Transactions of the Institute of Measurement and Control, 36(3), 367-374.

21. Aslam, M., Azam, M., and Jun, C. H. (2014). A new exponentially weighted moving average sign chart using repetitive sampling. Journal of Process Control, 24(7), 1149-1153.

22. Lio, Y. L., Tsai, T. R., Aslam, M., and Jiang, N. (2014). Control charts for monitoring Burr type-X percentiles. Communications in Statistics-Simulation and Computation, 43(4), 761-776.

23. Aslam, M., Azam, M. Jun, C.-H. (2015a). A New Control Chart for Exponential Distributed Life Using EWMA, Transactions of the Institute of Measurement and Control, 37(2), 205-210.

24. Aslam, M., Azam, M., Khan, N. Jun, C.-H. (2015b). A Control Chart for an Exponential Distribution Using Multiple Dependent State Sampling, Quality and Quantity, 49, 455-462.

25. Aslam, M., Nazir, A. Jun, C.-H. (2015c). A New Attribute Control Chart using Multiple Dependent State Sampling, Transactions of the Institute of Measurement and Control, 37 (4), 569-576.

26. Azam, M., Aslam, M. and Jun, C.-H. (2015). Designing of a hybrid exponentially weighted moving average control chart using repetitive sampling, International Journal of Advanced Manufacturing Technology, 77, 1927-1933.

27. Aslam, M. and Jun, C.-H. (2015d). Attribute Control Charts for the Weibull Distribution under Truncated Life Tests, Quality Engineering, 27, 283-288.

28. Krishnamoorthy, K., Mathew, T., and Mukherjee, S. (2012). Normal-based methods for a gamma distribution. Technometrics.

29. Wilson, E. B., and Hilferty, M. M. (1931). The Distribution of Chi-Squares," Proceedings of the National Academy of Sciences, 17, 684-688.

30. Jun, C. H., Balamurali, S., and Lee, S. H. (2006). Variables sampling plans for Weibull distributed lifetimes under sudden death testing. IEEE Transactions on Reliability, 55(1), 53-58. 